\title{
Nutrition and prostate cancer: review of the evidence
}

\author{
Miruna Dragomir ${ }^{1}$, Patrick Mullie ${ }^{1}$, Maria Bota ${ }^{1,2}$, Alice Koechlin ${ }^{1,2}$, Alina Macacu ${ }^{1}$, Cécile Pizot ${ }^{1}$, Peter Boyle ${ }^{1,2}$ \\ IInternational Prevention Research Institute (iPRI), Lyon, France \\ 2Strathclyde University Global Public Health Institute, Lyon, France
}

\begin{abstract}
Objectives: Of the possible causes of cancer, nutritional factors are supposed to play a major role in preventable cancers. Regarding prostate cancer, nutritional data remain contradictory. This article aims to review current evidence on the relation between nutrition and prostate cancer.

Material and methods: A systematic literature search for meta-analyses, systematic reviews, and pooled analyses was conducted in the PubMed database from its inception to September 2019. Eligible studies had to assess the association between nutrition and risk of prostate cancer.

Results: Generally, no evidence was found for an association between most food items or groups, including fruit, vegetables, meat, tea, coffee, and risk of prostate cancer. There was an inconsistent and weak positive association between milk and dairy foods and prostate cancer. Carbohydrates, vitamins, and minerals were not associated with prostate cancer. Furthermore, no association was found with dietary patterns such as vegetarian or pesco-vegetarian, but increased adherence to a Mediterranean diet seemed to have a protective effect. In general, large heterogeneity between studies was observed. Studies included in meta-analyses were mostly observational, and therefore prone to several inherent biases.

Conclusions: The evidence on any potential association between diet and prostate cancer is weak. The reductionist approach considering individual nutritional factors is not suitable, and conducting more observational studies or small randomised trials evaluating the impact of individual nutritional factors on prostate cancer will not bring further answers. Large, well-designed, randomised, controlled trials are mandatory in order to clarify the relationship between nutrition and prostate cancer.
\end{abstract}

KEY WORDS: diet, prostate cancer, review, nutrition, dietary patterns, dietary factors, dietary supplements.

ADDRESS FOR CORRESPONDENCE: Miruna Dragomir, International Prevention Research Institute (iPRI),

95 Cours Lafayette, 69006 Lyon, France, e-mail: miruna.dragomir@i-pri.org

\section{INTRODUCTION}

In the 1980s, nutrition was estimated to contribute to the development of more than one third of cancers (35\%) in Western countries [1], which made nutrition the second most important preventable cause of cancer, after smoking.

According to the latest burden of disease study, almost 530,000 deaths in 2016 in the US were attributed to dietary factors [2], which corresponds to approximately $19.3 \%$ of the total number of deaths in the United States of America (USA).
Prostate cancer is the second most commonly diagnosed cancer in men: almost 1.3 million men in the world were projected to be diagnosed with prostate cancer in 2018 [3]. Moreover, with an estimated number of associated deaths of 359,000 in 2018, prostate cancer is the fifth leading cause of death from cancer in men [3].

While prostate cancer aetiology remains mostly unknown, an association with nutritional factors is plausible; since prostate cancer presents a long latency, diet and nutrition might have an impact on its pro- 
gression at several stages of the life cycle. Nonetheless, existing evidence supporting this association is mainly inconsistent [4-6].

Therefore, the aim of this article was to review the current evidence of the impact of several dietary factors on the risk of prostate cancer.

\section{METHODS}

A systematic literature search was conducted to identify meta-analyses or systematic reviews assessing the association between nutrition and prostate cancer. The literature search was restricted to articles published in English in the PubMed database from its inception to September 2019. A combination of key words and $\mathrm{MeSH}$ index terms was used including "prostate cancer" or "prostate neoplasm", "diet" or "dietary" or "dietary intake" and "meta-analysis" or "pooled analysis". Complementary searches were also conducted; more details are reported in the supplementary material (Appendix 1).

Eligible articles had to 1) present a meta-analysis or a pooled analysis of retrospective or prospective studies, and 2) report a summary estimate on risk of prostate cancer associated with either a measurement of food intake (dietary intake or supplementation) or with a measurement of the adherence to a dietary pattern.

Titles and abstracts were screened for eligibility. Full copies of eligible articles were retrieved and fully read.

For each article, the following information was extracted: the number and the design (cohort, case-control, or randomised controlled trial) of the included studies, total number of prostate cancer cases, sample size of the study, mean follow-up period, and the summary estimate with its corresponding confidence interval (CI). Moreover, information on the publication bias (type of assessment and results with $p$-value) as well as on the between-study heterogeneity ( $\mathrm{I}^{2}$ or $p$-value) were also extracted.

\section{RESULTS}

The literature search yielded 68 published meta-analyses investigating the association between nutrition and prostate cancer risk. The nutritional topics that were investigated were: vitamins and minerals (11 articles); fruit, vegetables, and carotenoids (11 articles); fat and fatty acids (10 articles); meat (11 articles); milk and dairy (seven articles); carbohydrates (four articles) and other dietary items (seven articles). Also, seven articles reported on the association between dietary patterns and risk of prostate cancer. Results in terms of strength and direction of the association are summarised in Table 1.

\section{VITAMINS AND MINERALS}

Eleven meta-analyses assessed the relationship between vitamins and/or minerals dietary intake or supplementation and risk of prostate cancer [7-17] (Appendix 2).

Overall, there was no statistically significant association between vitamin intake or supplementation and risk of prostate cancer, regardless of the type of vitamin and the study design. Only one meta-analysis of 18 observational studies found a significant decrease of $11 \%$ in prostate cancer risk when comparing highest and lowest dietary intake levels of vitamin C, with low to moderate heterogeneity $\left(\mathrm{I}^{2}=39.4 \%\right)$ and no evidence of publication bias [7]. An earlier published meta-analysis [9], including two randomised, controlled trials (RCTs), compared vitamin C supplementation with placebo and found no association (summary relative risk $[\mathrm{SRR}]=0.98$ [95\% CI: 0.91, 1.06]).

Five meta-analyses investigated the association between folic acid intake and risk of prostate cancer. Meta-analyses of observational studies did not suggest an association when comparing highest and lowest intakes of folate, with reported SRRs ranging from 0.83

TABLE 1. Summary of found evidence

\begin{tabular}{|l|l|l|}
\hline \multicolumn{1}{|c|}{ Decreases risk } & \multicolumn{1}{|c|}{ Increases risk } \\
\hline Strong evidence & - & - \\
\hline Probable evidence & $\begin{array}{l}\text { Nutrients: lycopene } \\
\text { Dietary patterns: adherence to WCRF/AICR } \\
\text { dietary recommendations }\end{array}$ & Food items/food groups: milk and dairy \\
\hline $\begin{array}{l}\text { Limited-suggestive } \\
\text { evidence }\end{array}$ & $\begin{array}{l}\text { Nutrients: alpha-carotene, calcium } \\
\text { Food items/food groups: } \\
\text { - tofu, soy food } \\
\text { - tomato } \\
\text { - whole milk } \\
\text { Dietary patterns: Mediterranean diet }\end{array}$ & $\begin{array}{l}\text { Nutrients: } \\
\text { - flavonoids } \\
\text { - folic acid } \\
\text { Food items/food groups: fried food }\end{array}$ \\
\hline $\begin{array}{l}\text { No evidence for } \\
\text { an association }\end{array}$ & $\begin{array}{l}\text { Nutrients: carbohydrates, vitamins (C, D, E, multivitamins), minerals, beta-carotene } \\
\text { Food items/food groups: fruit and vegetables, meat and alternatives to meat (fish, seafood), } \\
\text { eggs, tea, coffee, dietary acrylamide } \\
\text { Dietary patterns: vegetarian, semi-vegetarian, and pesco-vegetarian diets }\end{array}$ \\
\hline
\end{tabular}


(95\% CI: $0.57,1.20)$ to 1.02 (95\% CI: $0.95,1.09)$. Low to moderate amounts of heterogeneity were observed, with higher heterogeneity in case-control $\left(\mathrm{I}^{2}=57.7 \%\right)$ compared to cohort studies $\left(\mathrm{I}^{2}=0 \%\right)$. Summary relative risks were higher in RCTs compared to observational studies, but in two out of three meta-analyses, the association between intake of folate and risk of prostate cancer was not statistically significant. On the other hand, a meta-analysis of five RCTs found a significantly increased risk of $24 \%$ in patients randomised to folic acid compared to those randomised to placebo.

There was no association between zinc intake and risk of prostate cancer in two meta-analyses $[10,12]$, but the results remained heterogeneous ( $\mathrm{I}^{2}$ of 23.8 and $90 \%$, respectively), and were based on a limited number of studies included in the analyses.

The results of studies investigating selenium intake and prostate cancer risk were inconsistent. A recently published Cochrane review of 21 observational studies found a statistically significant risk reduction of $16 \%$ when comparing highest and lowest selenium intake levels [14], with low heterogeneity across studies and no evidence of publication bias. However, the same review reported no association between selenium intake and prostate cancer risk in an analysis based on four RCTs. Similarly, two other meta-analyses $[9,12]$ found no association between selenium supplementation and risk of prostate cancer, but included a limited number of studies that were very heterogeneous ( $\mathrm{I}^{2}$ of $84 \%$ and $96 \%$, respectively).

\section{FRUIT, VEGETABLES, AND CAROTENOIDS}

Eleven meta-analyses reported on the association between fruit, vegetable, and carotenoid intake or supplementation and prostate cancer risk [9, 12, 18-26] (Appendix 3).

Two meta-analyses investigated concomitantly the relationship between fruit and vegetable intake and prostate cancer $[22,23]$, both finding no association between fruit intake and prostate cancer, with no significant heterogeneity and no evidence of publication bias. Moreover, a more recent meta-analysis found no association with prostate cancer when comparing highest and lowest quartiles of apple consumption. No association was found between vegetable intake and risk of prostate cancer.

Three meta-analyses reported on the association between raw and cooked tomato intake and risk of prostate cancer $[18,20,24]$. The most recent and largest one, published by Rowles et al. [24], reported a significantly reduced risk of prostate cancer when comparing highest and lowest intakes of total tomato, tomato foods, and cooked tomato and sauces, with corresponding SRRs of 0.81 (95\% CI: 0.71, 0.92), 0.84 (95\% CI: 0.72, 0.98), and 0.84 (95\% CI: 0.73, 0.99), respectively. However, heter- ogeneity between studies remained high $\left(\mathrm{I}^{2}\right.$ of $73.1 \%$, $76.7 \%$, and $57.4 \%$, respectively) and statistical tests suggested publication bias.

On the other hand, five meta-analyses of observational studies examined the association between lycopene intake - a carotenoid found in particularly large amounts in tomatoes and associated products - and risk of prostate cancer $[18-20,25,26]$. An overall reduced risk of prostate cancer was observed with increasing consumption of lycopene, with risk reductions ranging from 3 to $12 \%$ across these studies.

In the most recent meta-analysis, based on 25 observational studies, the decreased risk was statistically significant (SRR $=0.88$ [95\% CI: 0.78, 0.98]), when comparing highest and lowest categories of lycopene intake. However, there was significant between-study heterogeneity $\left(\mathrm{I}^{2}=56.7 \%, p=0.001\right)$ and Begg's test suggested potential publication bias. When stratified by study design (e.g. cohort vs case-control studies), the association remained significant only for cohort studies, with a higher pooled estimate (SRR $=0.93$ [95\% CI: 0.79, $0.99]$ ), when compared to case-control studies ( $\mathrm{SRR}=$ 0.83 [95\% CI: 0.67, 1.02]). Between-study heterogeneity was higher in case-control studies $(65.5 \%)$ when compared to cohort studies (11\%).

Fewer meta-analyses reported on the association between other carotenoids and prostate cancer risk. When comparing highest and lowest intake levels of a-carotene from 12 observational studies, we found a borderline significant reduction of $13 \%$ in prostate cancer risk. On the other hand, no association was found between $\beta$-carotene dietary intake and/or supplementation and risk of prostate cancer in observational studies and RCTs $[9,12,26]$, with SRRs ranging from 0.90 to 1.18 .

\section{FAT AND FATTY ACIDS}

Ten meta-analyses reported on the association between fat and/or fatty acids intake and risk of prostate cancer [27-36] (Appendix 4).

Two meta-analyses examined the relationship between total, saturated, and unsaturated fat intake and prostate cancer risk $[32,35]$. Both found no association between saturated or unsaturated fat and risk of prostate cancer. However, results were divergent for total fat, with one meta-analysis finding a significantly increased risk $(\mathrm{SRR}=1.17$ [95\% CI: 1.10, 1.25]), and the other finding no association (SRR $=1.00$ [95\% CI: 0.99, 1.01]).

Concerning fatty acids, seven meta-analyses reported on the association between intake of alpha-linolenic acid (ALA) and prostate cancer. Only two meta-analyses found an increased risk of prostate cancer associated with ALA intake $[28,32]$. In the other five meta-analyses, there was no association between ALA intake and risk of prostate cancer, with SRRs varying from 0.95 to 1.30 , 
which were higher in case-control studies compared to cohort studies. Overall, there was no evidence of publication bias, and heterogeneity ranged from 0 to $90 \%$.

Regarding intake of eicosapentaenoic acid (EPA) and docosahexaenoic acid (DHA), current evidence suggests there is no association with prostate cancer risk, with SRRs ranging from 0.99 to 1.11 . There were low to large amounts of heterogeneity ( $\mathrm{I}^{2}$ ranging from 0 to $\left.61 \%\right)$ and most studies lacked reporting of publication bias.

There seemed to be no evidence of an association between linoleic acid intake in two meta-analyses reporting relevant data, with SRRs ranging from 0.83 to 1.27 , which were larger in analyses based on case-control studies compared to analyses based on cohort studies.

Of note, in most analyses, the reporting on publication bias and heterogeneity was incomplete, and the number of included studies was limited.

\section{MEAT, FISH, SEAFOOD, ALTERNATIVES TO MEAT, AND EGGS}

Eleven meta-analyses reported on the association between meat, alternatives to meat, fish, seafood, and/or egg intakes and risk of prostate cancer [37-47] (Appendix 5).

Three meta-analyses suggested there was no association between red meat intake and risk of prostate cancer, regardless of the type of red meat (processed or unprocessed), with SRRs ranging from 0.99 to 1.06. In most analyses, funnel plots and publication bias tests suggested potential publication bias, and between-study heterogeneity ranged from 0 to $61 \%$. Also, based on pooled results from 15 cohort studies, there was no evidence of an association between poultry or seafood and prostate cancer risk [44].

Szymanski et al. [43] investigated the relationship between fish consumption and prostate cancer separately in 12 case-control and 12 cohort studies and found divergent results, with SRRs of 0.85 (95\% CI: 0.72, 1.00) and 1.01 (95\% CI: 0.90, 1.14), respectively.

Based on four meta-analyses of cohort and case-control studies, higher intakes of tofu and/or soy food were generally associated with a significantly lower risk of prostate cancer, in comparison with lower intakes, with corresponding SRRs ranging from 0.65 to 0.75 . The most recent meta-analysis published by Applegate et al. [38] reported risk reductions of $19 \%$ and $17 \%$ when comparing highest and lowest consumption of total soy food and tofu, respectively.

No association was found between isoflavones (generally found in soy) and risk of prostate cancer [38, 47].

Results from three meta-analyses suggested no association between intake of eggs and risk of prostate cancer, regardless of the study design (cohort vs case-control) and the quantification of eggs intake. There was no evidence of publication bias, and heterogeneity was low to moderate ( $\mathrm{I}^{2}$ ranging from 0 to $52.2 \%$ ). However, based on four studies, Keum et al. [41] found a significantly increased risk of fatal prostate cancer associated with egg intake (SRR = 1.47 [95\% CI: 1.01, 2.14]) with moderate heterogeneity $\left(\mathrm{I}^{2}=40 \%\right)$.

More generally, there was no association between protein intake and risk of prostate cancer [42].

\section{MILK, DAIRY PRODUCTS, AND SOURCES OF CALCIUM}

Seven meta-analyses investigated the association between milk, dairy, and/or calcium dietary intakes and supplementation and risk of prostate cancer [48-54] (Appendix 6).

In the most complete meta-analysis of cohort studies, Aune et al. [48] suggested that high intakes of total dairy, milk, low-fat milk, cheese, total calcium, dietary calcium, and dairy calcium were associated with increased risk of prostate cancer, when compared to lower intakes. Corresponding SRRs varied from 1.07 to 1.18 , with low to moderate between-study heterogeneity ( $\mathrm{I}^{2}$ ranging from 0 to 53\%). Conversely, high intakes of whole milk were associated with an $8 \%$ decrease in prostate cancer risk, when compared to lower intakes. There was no significant association between other types of dairy products such as yoghurt, non-dairy calcium, and supplemental calcium intakes and prostate cancer risk. Overall, results from other meta-analyses of observational studies were consistent with those of Aune et al. [48].

However, in a meta-analysis of seven RCTs, Bristow et al. [49] found a significant $46 \%$ reduction in prostate cancer risk when comparing calcium supplementation and placebo.

\section{CARBOHYDRATES, DIETARY FIBRE, GLYCAEMIC LOAD, AND GLYCAEMIC INDEX}

Four meta-analyses reported on the association between carbohydrates, dietary fibre, and whole grain intake and risk of prostate cancer [55-58] (Appendix 7). One meta-analysis also investigated the relationship between glycaemic index (GI), glycaemic load (GL), and prostate cancer [57].

Based on 17 studies, Sheng et al. [56] found a decrease in the risk of prostate cancer when comparing highest and lowest dietary fibre intakes, with significant heterogeneity $\left(\mathrm{I}^{2}=53.6 \%, p=0.005\right)$. No evidence of publication bias was observed. When stratifying the analysis by study design, the decreased risk was statistically significant in case-control studies, with no heterogeneity, but not significant in cohort studies, with very large heterogeneity.

Wang et al. [57] investigated the potential association between dietary fibre intake, whole grains, carbohydrates, glycaemic index (GI), and glycaemic load (GL) and risk of prostate cancer in a systematic review 
of 27 studies. The authors found no clear evidence of a relationship with prostate cancer risk. Funnel plot inspection and Egger's and Begg's tests suggested no evidence of publication bias. Heterogeneity was generally moderate, ranging from 39.5 to $69.5 \%$ for dietary fibre intake and GI, respectively.

Based on five cohorts and 16 case-control studies, Fan et al. [55] found no association between carbohydrate intake and prostate cancer risk. Funnel plot inspection and statistical tests indicated no evidence of publication bias. Significant heterogeneity among included studies was observed $\left(\mathrm{I}^{2}=62.7 \%\right)$. Results were not altered when the analysis was stratified by study design (data not shown); however, larger heterogeneity was observed in case-control studies when compared to cohorts $(68.5 \%$ vs $7.8 \%$ ). Results published in a previous meta-analysis are also consistent [58].

\section{OTHER DIETARY ITEMS}

Seven meta-analyses reported on the association between intake of other dietary items or food groups and risk of prostate cancer [59-65]. Dietary items/groups assessed were various and included tea, and coffee, flavonoids, fried food, and dietary acrylamide (Appendix 8).

Based on seven cohort studies, there was no association between tea consumption and risk of prostate cancer. Results regarding coffee intake were inconsistent: when comparing highest and lowest intakes, two meta-analyses of 13 and five prospective studies reported significant protective effects of coffee, with risk reductions of $10 \%$ [59] and 21\% [64], respectively. Conversely, another meta-analysis of 12 observational studies found a significant harmful effect of coffee [62].

Increased intake of flavonoids was also associated with significant increases in risk of prostate cancer. However, results seemed to be driven by one large study; after its removal from the analysis, the pooled estimate lost statistical significance.

Also, fried food seemed to increase the risk of prostate cancer, but the limited number as well as the case-control design of the included studies imply caution when interpreting these results

Finally, no association was found between intake of dietary acrylamide and prostate cancer.

\section{DIETARY PATTERNS}

Seven meta-analyses assessed the relationship between different dietary patterns and risk of prostate cancer [66-72] (Appendix 9).

When comparing highest and lowest adherence to healthy dietary patterns, two meta-analyses found no association with prostate cancer $[67,69]$. On the other hand, Fabiani et al. [67] reported a significantly increased risk of prostate cancer associated with highest adherence to western and carbohydrate dietary patterns (consid- ered unhealthy), with corresponding increases in risk of $34 \%$ and $64 \%$, respectively. Based on seven case-control studies, Grosso et al. [69] reported a similar estimate, with a $44 \%$ increase in risk associated with higher adherence to unhealthy dietary patterns. Nonetheless, this association was not observed in cohort studies.

No association with risk of prostate cancer was found when comparing vegetarian, pesco-vegetarian, and semi-vegetarian diets to a non-vegetarian diet, based on results pooled from four, four, and two cohort studies, respectively [69].

The most recent meta-analysis investigating the Mediterranean diet - high in vegetables, olive oil, complex carbohydrates, lean meats, and antioxidants - was found to decrease the risk of prostate cancer by $5 \%$, with no heterogeneity. However, this decrease was not statistically significant, and the authors suggested potential publication bias. Results from two other previously published meta-analyses were also consistent $[71,72]$.

Furthermore, a meta-analysis of seven cohort studies suggested that adherence to the World Cancer Research Fund and American Institute for Cancer Research (CRF/ AICR) dietary recommendations was associated with a significantly lower risk of prostate cancer. These dietary recommendations included: limiting the consumption of energy-dense foods and avoiding sugar-sweetened beverages, eating mostly foods of plant origin, reducing consumption of red meat and avoiding that of processed meat, and limiting alcoholic beverages [70].

\section{DISCUSSION}

The relationships between nutrition and prostate cancer risk have been the subject of a myriad systematic reviews, and this article provides a comprehensive overview of these publications.

Current evidence does not support an association between carbohydrates, fat and fatty acids, fruit and vegetables, meat and alternatives for meat, vitamins, minerals, and tea and risk of prostate cancer.

Several meta-analyses of observational studies suggested a positive association between milk and dairy and prostate cancer risk. Regarding calcium, results were inconsistent between observational studies and randomised trials, the latter suggesting a protective effect of calcium when compared to placebo. These contradictory results among types of dairy products and sources of calcium suggest that other elements instead of fat and calcium might be responsible for the increase in risk of prostate cancer.

Conversely, a potentially beneficial role of lycopene was detected in observational studies. Lycopene is found in high concentration in the prostate and is the most potent antioxidant among the carotenoids [73, 74]. It is thought that through its antioxidant powers, lycopene could reduce DNA damage in the prostate 
[75]. However, further research is needed in order to better understand the mechanisms of absorption and degradation of lycopene in the prostate as well as other factors modulating these mechanisms, which remain mostly unknown $[73,76]$.

However, a "reductionist" approach considering intake of single foods and prostate cancer risk may not be the most suitable approach. The literature is overwhelmed with such studies: there are peer-reviewed publications associating cancer with almost every existent single aliment [77]. Considering dietary patterns instead of single nutrients or foods might be more appropriate because they are generally not consumed separately and the health-related effects could be interdependent [78].

Regarding dietary patterns, adhering to a Mediterranean diet seemed to have a slightly protective effect on the risk of prostate cancer, but the association was not statistically significant. Adherence to WCRF/AICR dietary recommendations was also found to be associated with a decreased risk of prostate cancer. On the other hand, dietary patterns such as vegetarian or pesco-vegetarian did not seem to be associated with prostate cancer.

Our study attempted to present a comprehensive overview of the epidemiology of prostate cancer. However, some limitations should be addressed. Firstly, generally large amounts of between-study heterogeneity were observed. This heterogeneity could be explained by differences across studies in the definition of the categories of intake. For some foods or food groups, either their myriad of definitions (e.g. fibre, carbohydrate) or their heterogeneous reporting and measurement (e.g. fat intake) could account for large parts of the observed between-study heterogeneity.

Secondly, studies included in meta-analyses were generally observational (cohort and case-control studies) and therefore prone to several inherent biases such as selection bias or information bias, particularly recall bias.

The observed associations may be due to confounding factors. For instance, food intake can be the reflection of a more general behaviour, e.g. people who eat well have other healthy behaviours, such as exercising, not smoking, are less obese, etc. Other socioeconomic factors such as social class can also be a source of confounding. Thus, the observed associations could be more the result of confounding by the aforementioned lifestyle factors than a causal nutrition-prostate cancer risk relationship. These aspects also need to be taken into consideration when interpreting these results. Further studies, and in particular well-designed randomised controlled trials, are mandatory to estimate the levels of evidence and attempt to better clarify the associations between nutrition and prostate cancer.
Overall, evidence for associations was at best probable, but in most of the cases it remained suggestive/ limited; however, this is part of a much bigger picture: generally, studies investigating associations between malignancies and nutritional ingredients are based on weak evidence [77]. Also, one problematic aspect of observational studies on nutrition is that they measure dietary intake only once (e.g. at baseline); however, dietary intake during follow-up are not necessarily reflected by the baseline measured consumption [79]. Measuring food intake or adherence to dietary patterns more than once could be more appropriate.

The lack of association and the inconclusiveness of results might also be a result of weakness of evidence, small effect sizes, and nutritional studies' flawed assessment of dietary intake.

Based on existent evidence, it remains difficult to draw conclusions regarding the relationship between diet and prostate cancer. It is disappointing to see that despite the great number of published studies, very few associations stand out. Another myriad of observational studies or small randomised trials will not bring further answers [80]. More specifically, large, well-designed, randomised, controlled trials, are required in order to obtain stronger levels of evidence and attempt to better clarify the associations between dietary factors and prostate cancer risk. Orienting future research towards other nutrition-related topics (e.g. food security, climate change as a consequence of food production, differential food access due to social inequalities, etc.) would potentially help better comprehend ways in which nutrition influences cancer, and more specifically, prostate cancer.

\section{DISCLOSURE}

The authors report no conflict of interest.

\section{References}

1. Doll R, Peto R. The causes of cancer: quantitative estimates of avoidable risks of cancer in the United States today. J Natl Cancer Inst 1981; 66 (6): 1191-1308.

2. US Burden of Disease Collaborators, Mokdad AH, Ballestros K, et al. The state of US health, 1990-2016: burden of diseases, injuries, and risk factors among US states. JAMA 2018; 319 (14): 1444-1472.

3. Bray F, Ferlay J, Soerjomataram I, et al. Global cancer statistics 2018: GLOBOCAN estimates of incidence and mortality worldwide for 36 cancers in 185 countries. CA Cancer J Clin 2018; 68 (6): 394-424.

4. Lin PH, Aronson W, Freedland SJ. Nutrition, dietary interventions and prostate cancer: the latest evidence. BMC Med 2015; 13: 3 .

5. Lin PH, Aronson W, Freedland, SJ. An update of research evidence on nutrition and prostate cancer. Urol Oncol 2019; 37 (6): 387-401. 
6. Masko EM, Allott EH, Freedland SJ. The relationship between nutrition and prostate cancer: is more always better? Eur Urol 2013; 63 (5): 810-820.

7. Bai XY, Qu X, Jiang X, et al. Association between dietary vitamin $\mathrm{C}$ intake and risk of prostate cancer: a meta-analysis involving 103,658 Subjects. J Cancer 2015; 6 (9): 913-921.

8. Gilbert R, Martin RM, Beynon R, et al. Associations of circulating and dietary vitamin $\mathrm{D}$ with prostate cancer risk: a systematic review and dose-response meta-analysis. Cancer Causes Control 2011; 22 (3): 319-340.

9. Jiang L, Yang KH, Tian JH, et al. Efficacy of antioxidant vitamins and selenium supplement in prostate cancer prevention: a meta-analysis of randomized controlled trials. Nutr Cancer 2010; 62 (6): 719-727.

10. Mahmoud AM, Al-Alem U, Dabbous F, et al. Zinc intake and risk of prostate cancer: case-control study and meta-analysis. PLoS One 2016; 11 (11): e0165956.

11. Qin X, Cui Y, Shen L, et al. Folic acid supplementation and cancer risk: a meta-analysis of randomized controlled trials. Int J Cancer 2013; 133 (5): 1033-1041.

12. Stratton J, Godwin M. The effect of supplemental vitamins and minerals on the development of prostate cancer: a systematic review and meta-analysis. Fam Pract 2011; 28 (3): 243-252.

13. Tio M, Andrici J, Cox MR, Eslick GD. Folate intake and the risk of prostate cancer: a systematic review and meta-analysis. Prostate Cancer Prostatic Dis 2014; 17 (3): 213-219.

14. Vinceti M, Filippini T, Del Giovane C, et al. Selenium for preventing cancer. Cochrane Database Syst Rev 2018; 1: CD005195.

15. Vollset SE, Clarke R, Lewington S, et al. Effects of folic acid supplementation on overall and site-specific cancer incidence during the randomised trials: meta-analyses of data on 50000 individuals. Lancet 2013; 381 (9871): 1029-1036.

16. Wang R, Zheng Y, Huang JY, et al. Folate intake, serum folate levels, and prostate cancer risk: a meta-analysis of prospective studies. BMC Public Health 2014; 14: 1326.

17. Wien TN, Pike E, Wisloff T, et al. Cancer risk with folic acid supplements: a systematic review and meta-analysis. BMJ Open 2012; 2 (1): e000653.

18. Chen J, Song Y, Zhang L. Lycopene/tomato consumption and the risk of prostate cancer: a systematic review and meta-analysis of prospective studies. J Nutr Sci Vitaminol (Tokyo) 2013; 59 (3): 213-223.

19. Chen P, Zhang W, Wang X, et al. Lycopene and risk of prostate cancer: a systematic review and meta-analysis. Medicine (Baltimore) 2015; 94 (33): e1260.

20. Etminan M, Takkhouche B, Caamano-Isorna F. The role of tomato products and lycopene in the prevention of prostate cancer: a meta-analysis of observational studies. Cancer Epidemiol Biomarkers Prev 2004; 13 (3): 340-345.

21. Fabiani R, Minelli L, Rosignoli P. Apple intake and cancer risk: a systematic review and meta-analysis of observational studies. Public Health Nutr 2016; 19 (14): 2603-2617.

22. Meng H, Hu W, Chen Z, Shen Y. Fruit and vegetable intake and prostate cancer risk: a meta-analysis. Asia Pac J Clin Oncol 2014; 10 (2): 133-140.
23. Petimar J, Wilson KM, Wu K, et al. A pooled analysis of 15 prospective cohort studies on the association between fruit, vegetable, and mature bean consumption and risk of prostate cancer. Cancer Epidemiol Biomarkers Prev 2017; 26 (8): 1276-1287.

24. Rowles JL 3rd, Ranard KM, Applegate CC, et al. Processed and raw tomato consumption and risk of prostate cancer: a systematic review and dose-response meta-analysis. Prostate Cancer Prostatic Dis 2018; 21 (3): 319-336.

25. Rowles JL 3rd, Ranard KM, Smith JW, et al. Increased dietary and circulating lycopene are associated with reduced prostate cancer risk: a systematic review and meta-analysis. Prostate Cancer Prostatic Dis 2017; 20 (4): 361-377.

26. Wang Y, Cui R, Xiao Y, Fang J, Xu Q. Effect of carotene and lycopene on the risk of prostate cancer: a systematic review and dose-response meta-analysis of observational studies. PLoS One 2015; 10 (10): e0137427.

27. Alexander DD, Bassett JK, Weed DL, et al. Meta-analysis of long-chain omega-3 polyunsaturated fatty acids (L $\Omega$-3PUFA) and prostate cancer. Nutr Cancer 2015; 67 (4): 543-554.

28. Brouwer IA, Katan MB, Zock PL. Dietary alpha-linolenic acid is associated with reduced risk of fatal coronary heart disease, but increased prostate cancer risk: a meta-analysis. J Nutr 2004; 134 (4): 919-922.

29. Carayol M, Grosclaude P, Delpierre C. Prospective studies of dietary alpha-linolenic acid intake and prostate cancer risk: a meta-analysis. Cancer Causes Control 2010; 21 (3): 347-355.

30. Carleton AJ, Sievenpiper JL, de Souza R, et al. Case-control and prospective studies of dietary $\alpha$-linolenic acid intake and prostate cancer risk: a meta-analysis. BMJ Open 2013; 3 (5): e002280.

31. Chua ME, Sio MC, Sorongon MC, Dy JS. Relationship of dietary intake of omega-3 and omega- 6 fatty acids with risk of prostate cancer development: a meta-analysis of prospective studies and review of literature. Prostate Cancer 2012; 2012: 826254.

32. Dennis LK, Snetselaar LG, Smith BJ, et al. Problems with the assessment of dietary fat in prostate cancer studies. Am J Epidemiol 2004; 160 (5): 436-444.

33. Fu YQ, Zheng JS, Yang B, Li D. Effect of individual omega-3 fatty acids on the risk of prostate cancer: a systematic review and dose-response meta-analysis of prospective cohort studies. J Epidemiol 2015; 25 (4): 261-274.

34. Simon JA, Chen YH, Bent S. The relation of alpha-linolenic acid to the risk of prostate cancer: a systematic review and meta-analysis. Am J Clin Nutr 2009; 89 (5): 1558S-1564S.

35. Xu C, Han FF, Zeng XT, et al. Fat intake is not linked to prostate cancer: a systematic review and dose-response meta-analysis. PLoS One 2015; 10 (7): e0131747.

36. Zock PL, Katan MB. Linoleic acid intake and cancer risk: a review and meta-analysis. Am J Clin Nutr 1998; 68 (1): 142153.

37. Alexander DD, Mink PJ, Cushing CA, Sceurman B. A review and meta-analysis of prospective studies of red and processed meat intake and prostate cancer. Nutr J 2010; 9: 50. 
38. Applegate CC, Rowles JL, Ranard KM, et al. Soy consumption and the risk of prostate cancer: an updated systematic review and meta-analysis. Nutrients 2018; 10 (1): pii: E40.

39. Bylsma LC, Alexander DD. A review and meta-analysis of prospective studies of red and processed meat, meat cooking methods, heme iron, heterocyclic amines and prostate cancer. Nutr J 2015; 14: 125.

40. Hwang YW, Kim SY, Jee SH, et al. Soy food consumption and risk of prostate cancer: a meta-analysis of observational studies. Nutr Cancer 2009; 61 (5): 598-606.

41. Keum N, Lee DH, Marchand N, et al. Egg intake and cancers of the breast, ovary and prostate: a dose-response meta-analysis of prospective observational studies. Br J Nutr 2015; 114 (7): 1099-1107.

42. Mao Y, Tie Y, Du J. Association between dietary protein intake and prostate cancer risk: evidence from a meta-analysis. World J Surg Oncol 2018; 16 (1): 152.

43. Szymanski KM, Wheeler DC, Mucci LA. Fish consumption and prostate cancer risk: a review and meta-analysis. Am J Clin Nutr 2010; 92 (5): 1223-1233.

44. Wu K, Spiegelman D, Hou T, et al. Associations between unprocessed red and processed meat, poultry, seafood and egg intake and the risk of prostate cancer: A pooled analysis of 15 prospective cohort studies. Int J Cancer 2016; 138 (10): 2368-2382.

45. Xie B, He H. No association between egg intake and prostate cancer risk: a meta-analysis. Asian Pac J Cancer Prev 2012; 13 (9): 4677-4681

46. Yan L, Spitznagel EL. Meta-analysis of soy food and risk of prostate cancer in men. Int J Cancer 2005; 117 (4): 667-669.

47. Yan L, Spitznagel EL. Soy consumption and prostate cancer risk in men: a revisit of a meta-analysis. Am J Clin Nutr 2009; 89 (4): 1155-1163.

48. Aune D, Navarro Rosenblatt DA, Chan DS, et al. Dairy products, calcium, and prostate cancer risk: a systematic review and meta-analysis of cohort studies. Am J Clin Nutr 2015; 101 (1): 87-117

49. Bristow SM, Bolland MJ, MacLennan GS, et al. Calcium supplements and cancer risk: a meta-analysis of randomised controlled trials. Br J Nutr 2013; 110 (8): 1384-1393.

50. Gao X, LaValley MP, Tucker KL. Prospective studies of dairy product and calcium intakes and prostate cancer risk: a metaanalysis. J Natl Cancer Inst 2005; 97 (23): 1768-1777.

51. Huncharek M, Muscat J, Kupelnick B. Dairy products, dietary calcium and vitamin D intake as risk factors for prostate cancer: a meta-analysis of 26,769 cases from 45 observational studies. Nutr Cancer 2008; 60 (4): 421-441.

52. Qin LQ, Xu JY, Wang PY, et al. Milk consumption is a risk factor for prostate cancer: meta-analysis of case-control studies. Nutr Cancer 2004; 48 (1): 22-27.

53. Qin LQ, Xu JY, Wang PY, et al. Milk consumption is a risk factor for prostate cancer in Western countries: evidence from cohort studies. Asia Pac J Clin Nutr 2007; 16 (3): 467-476

54. Rahmati S, Azami M, Delpisheh A, et al. Total calcium (dietary and supplementary) intake and prostate cancer: a systematic review and meta-analysis. Asian Pac J Cancer Prev 2018; 19 (6): 1449-1456.
55. Fan LL, Su HX, Gu XJ, et al. Carbohydrate intake and the risk of prostate cancer. Clin Chim Acta 2018; 484: 60-71.

56. Sheng T, Shen RL, Shao H, Ma TH. No association between fiber intake and prostate cancer risk: a meta-analysis of epidemiological studies. World J Surg Oncol 2015; 13: 264.

57. Wang RJ, Tang JE, Chen Y, Gao JG. Dietary fiber, whole grains, carbohydrate, glycemic index, and glycemic load in relation to risk of prostate cancer. Onco Targets Ther 2015; 8: 2415-2426.

58. Zhai L, Cheng S, Zhang D. Dietary carbohydrate and prostate cancer risk: a meta-analysis. Nutr Cancer 2015; 67 (4): 594-602.

59. Grosso G, Godos J, Galvano F, Giovannucci EL. Coffee, caffeine, and health outcomes: an umbrella review. Annu Rev Nutr 2017; 37: 131-156.

60. Guo K, Liang Z, Liu L, et al. Flavonoids intake and risk of prostate cancer: a meta-analysis of observational studies. Andrologia 2016; 48 (10): 1175-1182.

61. Lippi G, Mattiuzzi C. Fried food and prostate cancer risk: systematic review and meta-analysis. Int J Food Sci Nutr 2015; 66 (5): 587-589.

62. Park CH, Myung SK, Kim TY, et al. Coffee consumption and risk of prostate cancer: a meta-analysis of epidemiological studies. BJU Int 2010; 106 (6): 762-769.

63. Pelucchi C, Bosetti C, Galeone C, La Vecchia C. Dietary acrylamide and cancer risk: an updated meta-analysis. Int J Cancer 2015; 136 (12): 2912-2922.

64. Yu X, Bao Z, Zou J, Dong J. Coffee consumption and risk of cancers: a meta-analysis of cohort studies. BMC Cancer 2011; 11: 96.

65. Zhang YF, Xu Q, Lu J, et al. Tea consumption and the incidence of cancer: a systematic review and meta-analysis of prospective observational studies. Eur J Cancer Prev 2015; 24 (4): 353-362.

66. Cheng S, Zheng Q, Ding G, Li G. Mediterranean dietary pattern and the risk of prostate cancer: A meta-analysis. Medicine (Baltimore) 2019; 98 (27): e16341.

67. Fabiani R, Minelli L, Bertarelli G, Bacci S. A Western dietary pattern increases prostate cancer risk: a systematic review and meta-analysis. Nutrients 2016; 8 (10): pii: E626.

68. Godos J, Bella F, Sciacca S, et al. Vegetarianism and breast, colorectal and prostate cancer risk: an overview and meta-analysis of cohort studies. J Hum Nutr Diet 2017; 30 (3): 349-359.

69. Grosso G, Bella F, Godos J, et al. Possible role of diet in cancer: systematic review and multiple meta-analyses of dietary patterns, lifestyle factors, and cancer risk. Nutr Rev 2017; 75 (6): 405-419.

70. Jankovic N, Geelen A, Winkels RM, et al. Adherence to the WCRF/AICR dietary recommendations for cancer prevention and risk of cancer in elderly from Europe and the United States: a meta-analysis within the CHANCES project. Cancer Epidemiol Biomarkers Prev 2017; 26 (1): 136-144.

71. Schwingshackl L, Hoffmann G. Adherence to Mediterranean diet and risk of cancer: a systematic review and meta-analysis of observational studies. Int J Cancer 2014; 135 (8): 1884-1897.

72. Schwingshackl L, Schwedhelm C, Galbete C, Hoffmann G. Adherence to Mediterranean diet and risk of cancer: an updated systematic review and meta-analysis. Nutrients 2017; 9 (10): pii: E1063. 
73. Bowen P, Chen L, Stacewicz-Sapuntzakis M, et al. Tomato sauce supplementation and prostate cancer: lycopene accumulation and modulation of biomarkers of carcinogenesis. Exp Biol Med (Maywood) 2002; 227 (10): 886-893.

74. Kucuk O, Sarkar FH, Sakr W, et al. Phase II randomized clinical trial of lycopene supplementation before radical prostatectomy. Cancer Epidemiol Biomarkers Prev 2001; 10 (8): 861-868.

75. Fraser ML, Lee AH, Binns CW. Lycopene and prostate cancer: emerging evidence. Expert Rev Anticancer Ther 2005; 5 (5): 847-854.

76. Agarwal S, Rao AV. Tomato lycopene and its role in human health and chronic diseases. CMAJ 2000; 163 (6): 739-744.

77. Schoenfeld JD, Ioannidis JP. Is everything we eat associated with cancer? A systematic cookbook review. Am J Clin Nutr 2013; 97 (1): 127-134.

78. Kant AK. Dietary patterns and health outcomes. J Am Diet Assoc 2004; 104 (4): 615-635.

79. Mullie P, Deforche B, Mertens E, et al. Low 10-year reproducibility of glycaemic index and glycaemic load in a prospective cohort study. Br J Nutr 2018; 120 (2): 227-230.

80. Ioannidis JP. Implausible results in human nutrition research. BMJ 2013; 347: f6698.

\section{AUTHORS' CONTRIBUTIONS}

MD, PB prepared research concept and design. MD collected data analysed them and wrote the article. PM critically revised the article. All authors contributed to preparing the final publication. 


\section{Appendix 1. Detailed literature search queries}

\section{MAIN LITERATURE SEARCH}

("prostate cancer" OR ("prostate" and "cancer") OR "Prostate Neoplasms"[MeSH] OR "prostate carcinoma" OR "prostatic cancer" OR ("prostatic" AND "cancer") OR ("prostatic" AND “neoplasms"))

AND

("diet" OR Diet[MeSH] or "dietary" or "dietary intake" or "nutrition")

AND

("meta-analysis" [Publication Type] OR "meta-analysis as topic" [MeSH] OR "meta-analysis" OR "pooled analysis")

\section{OTHER COMPLEMENTARY LITERATURE SEARCHES}

\section{VITAMIN D}

("prostate cancer" OR ("prostate" and "cancer") OR "Prostate Neoplasms"[MeSH] OR "prostate carcinoma" OR "prostatic cancer" OR ("prostatic" AND "cancer") OR ("prostatic" AND "neoplasms"))

AND

("Vitamin D"[Mesh] OR "vitamin D" OR "Ergocalciferols"[Mesh] OR "ergocalciferol" OR "Cholecalciferol”[Mesh] OR "Cholecalciferol")

AND

("meta-analysis" [Publication Type] OR "meta-analysis as topic"[MeSH] OR "meta-analysis" OR "pooled analysis")

RED MEAT

("prostate cancer" OR ("prostate" and "cancer") OR "Prostate Neoplasms"[MeSH] OR "prostate carcinoma" OR "prostatic cancer" OR ("prostatic" AND "cancer") OR ("prostatic" AND "neoplasms"))

AND

("red meat" or "meat")

AND

("meta-analysis" [Publication Type] OR "meta-analysis as topic" [MeSH] OR "meta-analysis" OR "pooled analysis") 


\begin{tabular}{|c|c|c|c|c|c|c|c|c|c|c|c|c|c|c|c|c|c|c|c|c|}
\hline 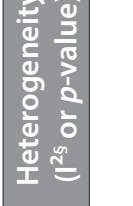 & 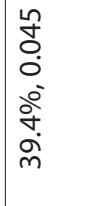 & $\begin{array}{l}\text { fे } \\
\text { o } \\
\text { ò }\end{array}$ & 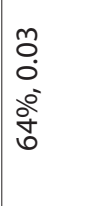 & $\begin{array}{l}\hat{2} \\
\hat{n} \\
0 \\
8 \\
0 \\
0\end{array}$ & 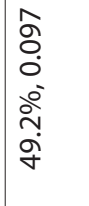 & $\begin{array}{l}\bar{\delta} \\
\vdots \\
0 \\
0 \\
o ̀ \\
\tilde{o}\end{array}$ & $\begin{array}{l}\text { On } \\
0 \\
0 \\
0 \\
0 \\
0 \\
0\end{array}$ & & $\begin{array}{l}0 \\
0 \\
0 \\
0 \\
0\end{array}$ & 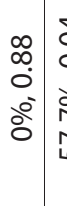 & 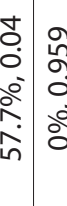 & $\begin{array}{l}0 \\
0 \\
0 \\
\circ \\
m \\
m \\
\dot{0} \\
\text { in }\end{array}$ & $\stackrel{\frac{c}{z}}{2}$ & $\begin{array}{c}\bar{m} \\
0 \\
\vdots \\
\vdots \\
\vdots \\
\vdots\end{array}$ & व̊ & 今े 今े & 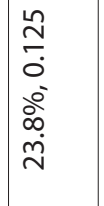 & $\begin{array}{l}\overline{8} \\
0 \\
0 \\
0 \\
0 \\
0 \\
0\end{array}$ & $\begin{array}{l}\overline{8} \\
\delta \\
0 \\
0 \\
o \\
o \\
o\end{array}$ & $\begin{array}{l}\bar{o} \\
0 \\
\vdots \\
o \\
\dot{o} \\
\infty\end{array}$ \\
\hline 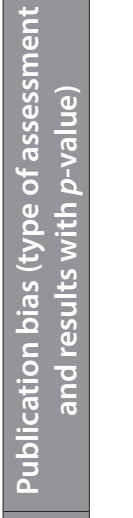 & 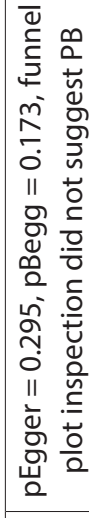 & $\frac{⿱}{z}$ & 愛 & 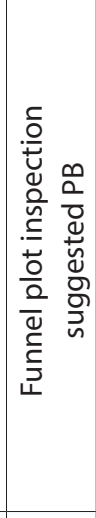 & 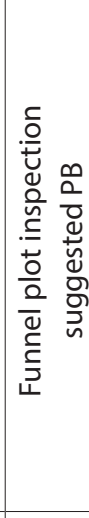 & $\frac{\mathscr{c}}{z}$ & 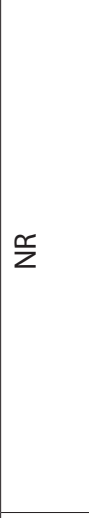 & & 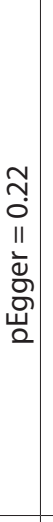 & 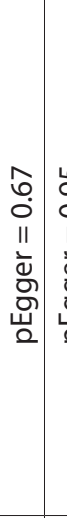 & 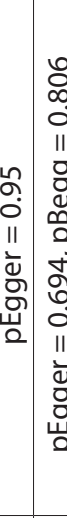 & $\frac{x}{2}$ & 受 & $\frac{\mathscr{c}}{z}$ & $\frac{9}{2}$ & 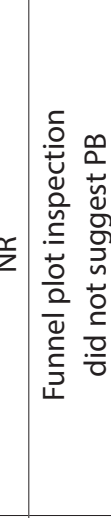 & 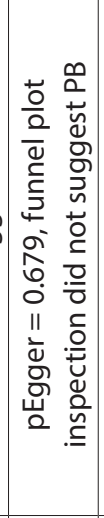 & 愛 & 受 & 受 \\
\hline 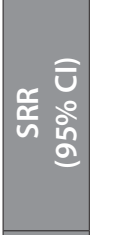 & $\begin{array}{l}\text { Fे } \\
o \\
0 \\
m \\
0 \\
0 \\
0 \\
0 \\
0 \\
0 \\
0\end{array}$ & 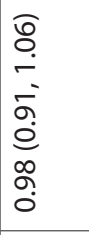 & 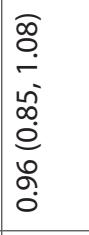 & 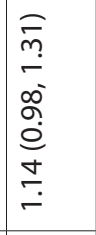 & 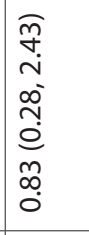 & $\begin{array}{l}0 \\
0 \\
i \\
0 \\
0 \\
0 \\
0 \\
1 \\
0 \\
-\end{array}$ & 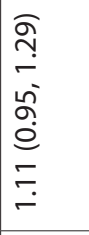 & & 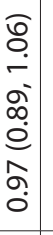 & 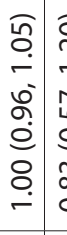 & 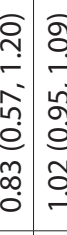 & 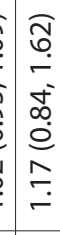 & 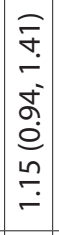 & 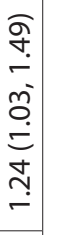 & $\begin{array}{l}2 \\
j \\
2 \\
\delta \\
o \\
\vdots \\
\vdots \\
2 \\
1\end{array}$ & 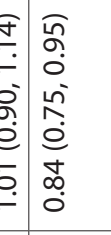 & $\begin{array}{l}0 \\
0 \\
\vdots \\
\infty \\
0 \\
0 \\
0 \\
0 \\
0 \\
0\end{array}$ & 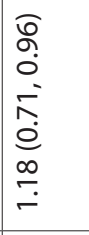 & $\begin{array}{l}\bar{\sigma} \\
\dot{m} \\
\infty \\
0 \\
0 \\
0 \\
\hat{0} \\
\end{array}$ & 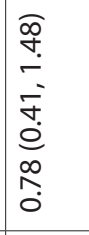 \\
\hline 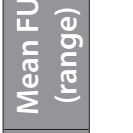 & $\stackrel{\Upsilon}{z}$ & $\overline{0}$ & ڤָ & $\stackrel{\circ}{\stackrel{1}{!}}$ & $\S$ & $\stackrel{*}{\stackrel{*}{n}}$ & @i & & 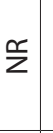 & $\frac{\mathfrak{c}}{z}$ & $\bar{z} \bar{J}$ & $\frac{\mathscr{c}}{z}$ & 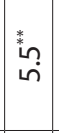 & $\overline{i n}$ & $\frac{9}{2}$ & $\frac{r}{z} \frac{\mathscr{r}}{z}$ & 愛 & $\stackrel{\frac{c}{z}}{z}$ & $\begin{array}{l}\text { Ln } \\
\text { in }\end{array}$ & $\begin{array}{l}n \\
0\end{array}$ \\
\hline 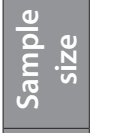 & $\begin{array}{l}0 \\
0 \\
0 \\
0 \\
0 \\
0 \\
0\end{array}$ & $\begin{array}{l}\widetilde{1} \\
\delta \\
\text { J }\end{array}$ & 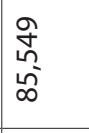 & $\begin{array}{l}\overline{0} \\
0 \\
0 \\
-\end{array}$ & $\begin{array}{l}\stackrel{2}{N} \\
\text { in }\end{array}$ & స̃ & $\begin{array}{l}\bar{n} \\
\infty \\
\infty \\
0 \\
n \\
m\end{array}$ & & $\begin{array}{l}2 \\
0 \\
0 \\
0 \\
1 \\
\end{array}$ & 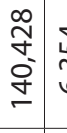 & 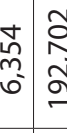 & $\begin{array}{l}n \\
\vdots \\
\vdots \\
i\end{array}$ & $\begin{array}{l}\hat{N} \\
\dot{f} \\
\end{array}$ & $\begin{array}{l}\infty \\
\stackrel{n}{n} \\
\\
\end{array}$ & $\begin{array}{l}\jmath \\
o \\
\alpha \\
1\end{array}$ & 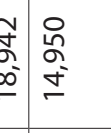 & $\begin{array}{l}2 \\
\frac{9}{E} \\
=\end{array}$ & $\begin{array}{l}\text { o } \\
o \\
0 \\
\dot{y}\end{array}$ & $\begin{array}{l}m \\
\tilde{N} \\
\stackrel{\nu}{N}\end{array}$ & $\begin{array}{l}8 \\
\stackrel{8}{\infty} \\
\infty \\
\infty\end{array}$ \\
\hline 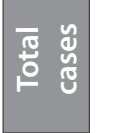 & 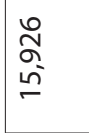 & 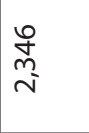 & $\begin{array}{l}\infty \\
\infty \\
1 \\
m \\
m\end{array}$ & $\begin{array}{l}\hat{\alpha} \\
\alpha \\
\text { nิ }\end{array}$ & 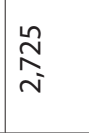 & 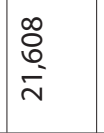 & $\begin{array}{c}\hat{\infty} \\
\infty \\
\tilde{m} \\
\end{array}$ & & $\begin{array}{l}\stackrel{\circ}{m} \\
\stackrel{m}{n} \\
\stackrel{n}{n}\end{array}$ & 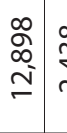 & 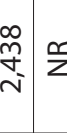 & ${ }_{i}^{\infty}$ & 总 & $\tilde{\tilde{\sigma}}$ & 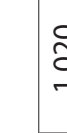 & $\begin{array}{l}0 \\
0 \\
= \\
=\end{array}$ & $\begin{array}{l}\stackrel{\mathscr{O}}{o} \\
\stackrel{0}{=} \\
=\end{array}$ & $\begin{array}{l}\text { ô } \\
\text { مิ } \\
\text { in }\end{array}$ & 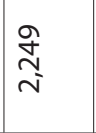 & $\tilde{\sigma}$ \\
\hline 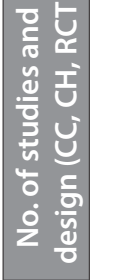 & 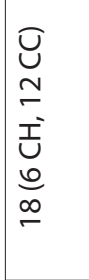 & $\stackrel{\substack{\check{r} \\
\sim}}{ }$ & $\begin{array}{l}\qquad \\
\propto \\
\text { in }\end{array}$ & 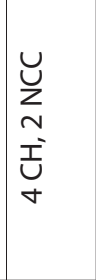 & $\underset{\text { in }}{\cup}$ & 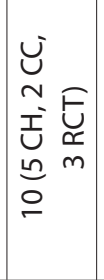 & 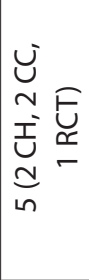 & & 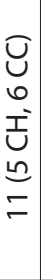 & I & 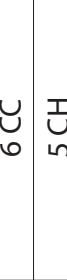 & 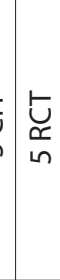 & $\mid \begin{array}{l}\mathfrak{E} \\
\underset{\sim}{\sim} \\
\underset{\sim}{\sim}\end{array}$ & 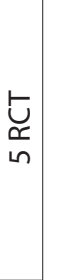 & 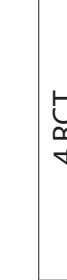 & 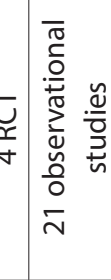 & 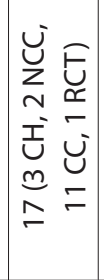 & 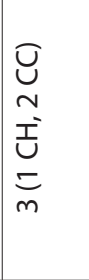 & 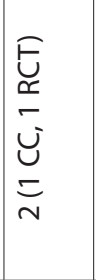 & $\underset{\sim}{\stackrel{一}{\sim}}$ \\
\hline 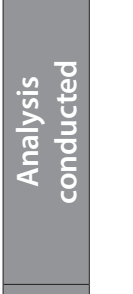 & 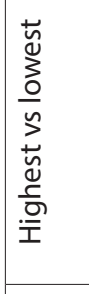 & 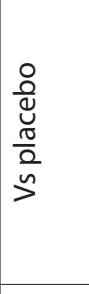 & 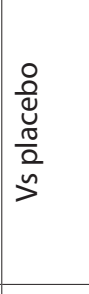 & 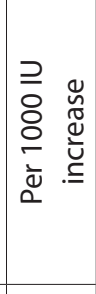 & 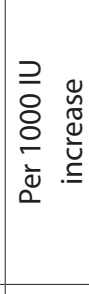 & 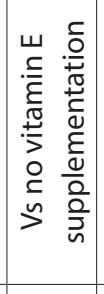 & 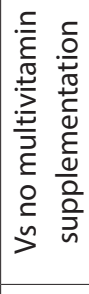 & & 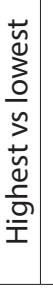 & 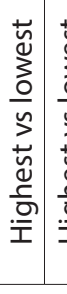 & 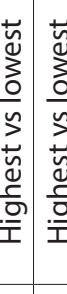 & 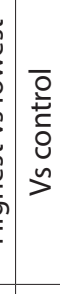 & $\mid \begin{array}{l}0 \\
\frac{0}{0} \\
\frac{\pi}{0} \\
\frac{0}{2} \\
>\end{array}$ & 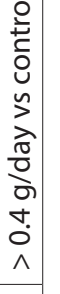 & 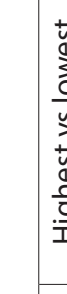 & 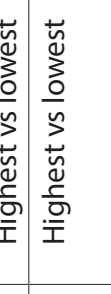 & 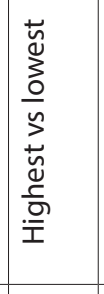 & 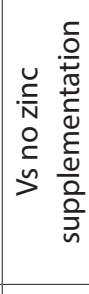 & 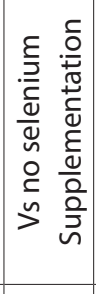 & $\begin{array}{l}\frac{8}{0} \\
\frac{0}{0} \\
\frac{\pi}{0} \\
> \\
>\end{array}$ \\
\hline 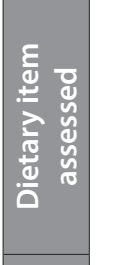 & 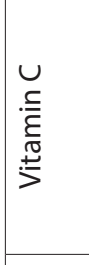 & 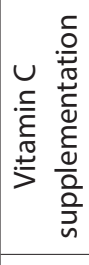 & 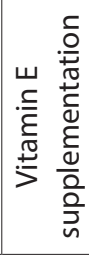 & 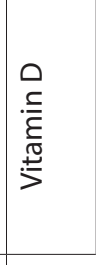 & 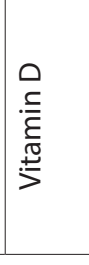 & 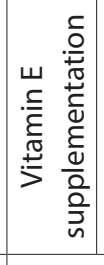 & 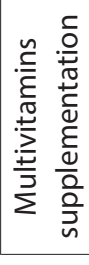 & & $\frac{\pi}{\frac{\pi}{0}}$ & & $\frac{5}{\frac{\pi}{0}}$ & 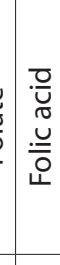 & 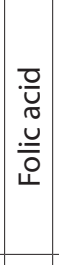 & 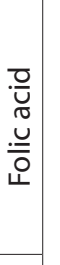 & 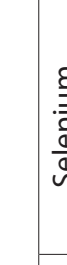 & 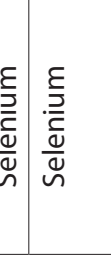 & $\stackrel{\breve{s}}{N}$ & 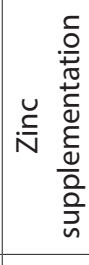 & 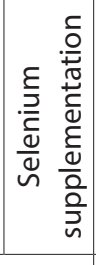 & 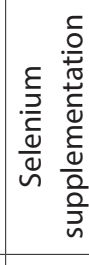 \\
\hline 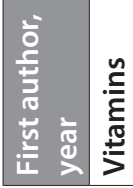 & 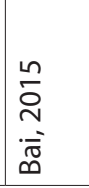 & 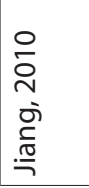 & & 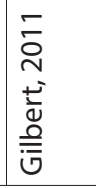 & & 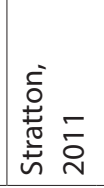 & & 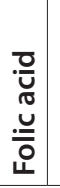 & 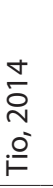 & & 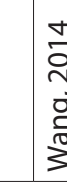 & 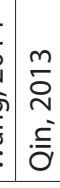 & 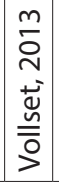 & 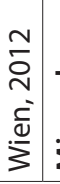 & 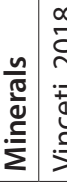 & & 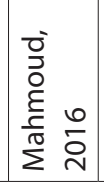 & 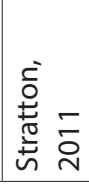 & & 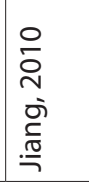 \\
\hline
\end{tabular}




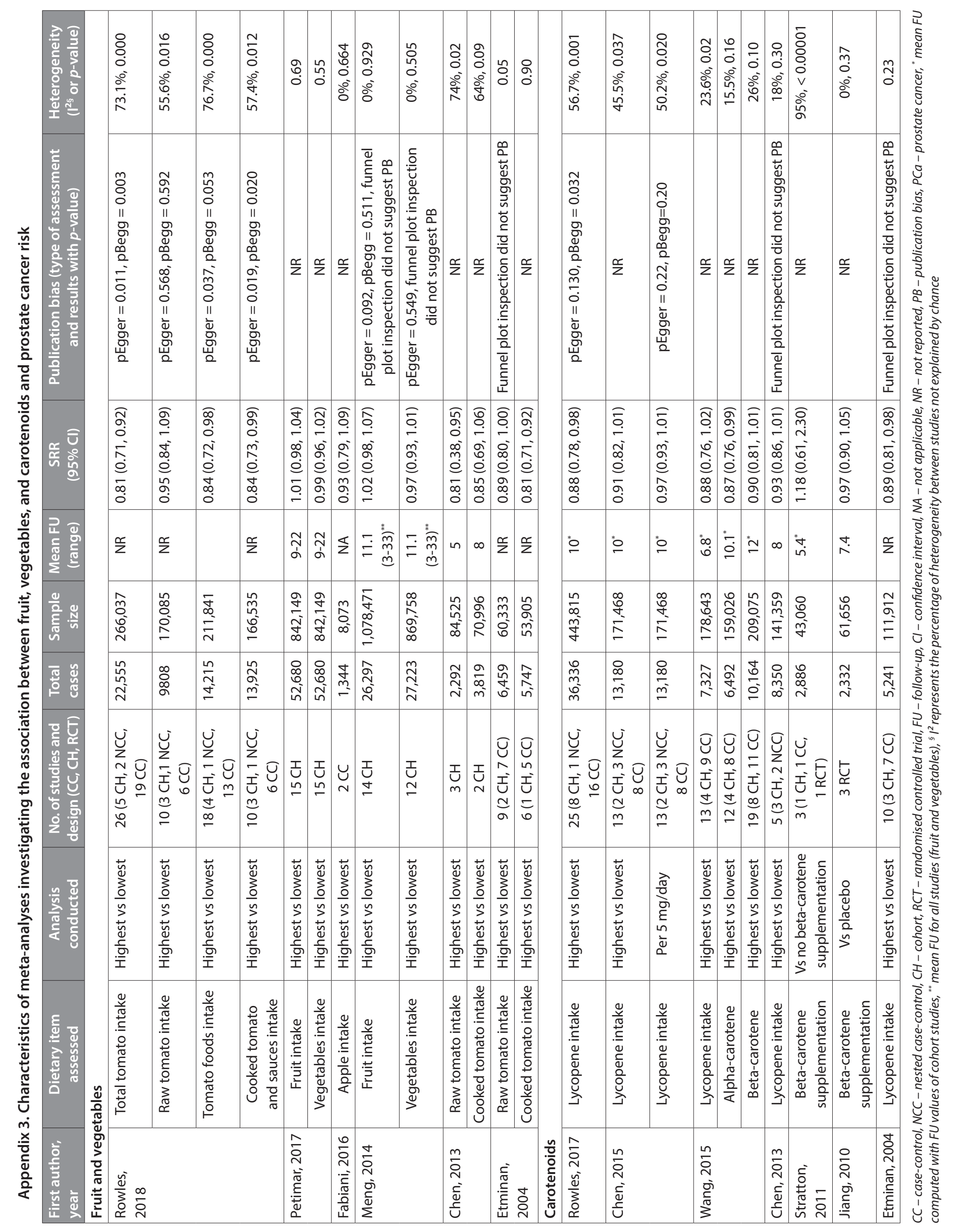


$4 \pi$

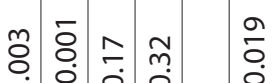

m.

v 00

১ें

in

官

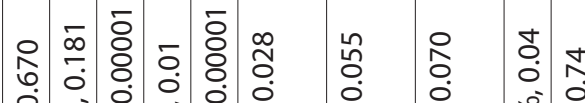

-

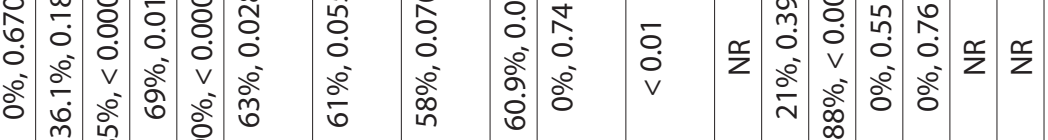

尔

훙

ก

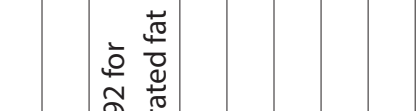

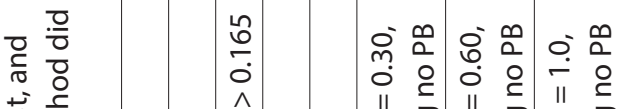

م.

II

ठ 응

岗

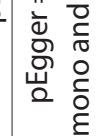

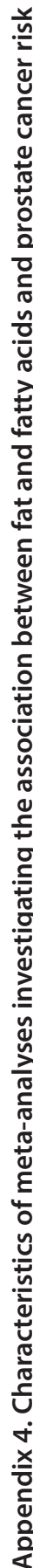

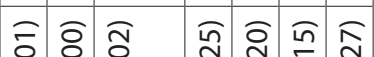

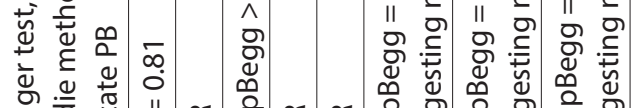

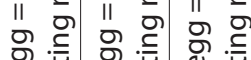

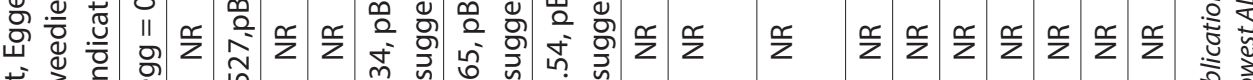

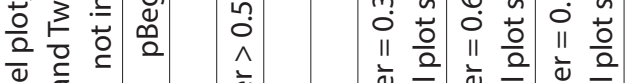

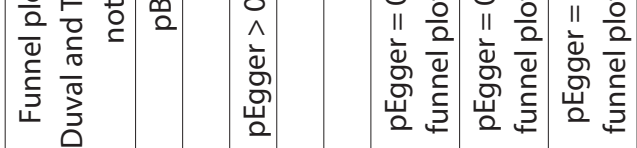

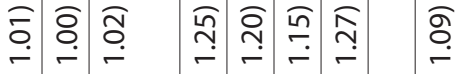

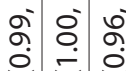

= 0

○ㅂ

尹

ก.

亡̇

ஸุ

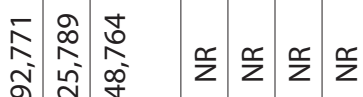

ชิ

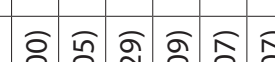

岗

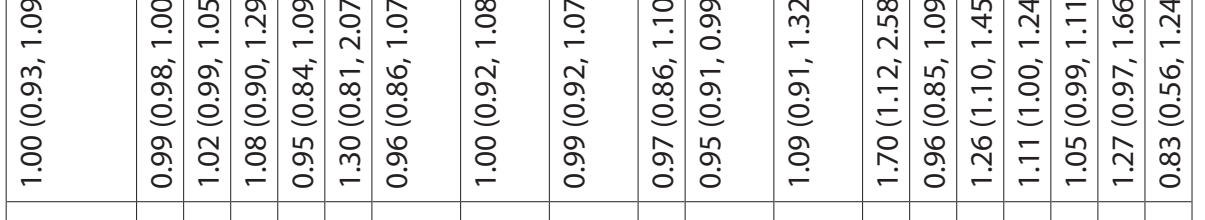

ชิ

ণิ

=

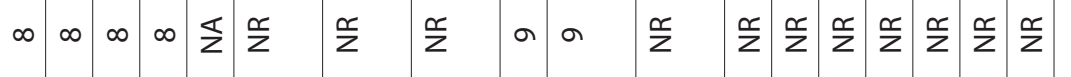

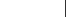

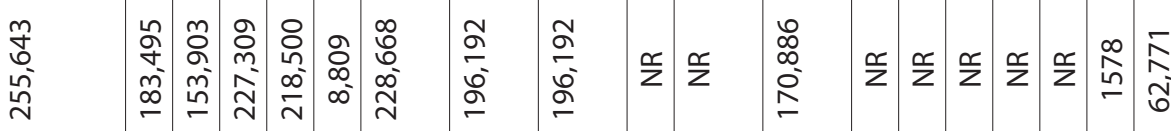

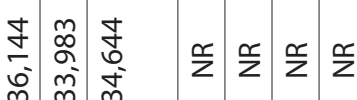

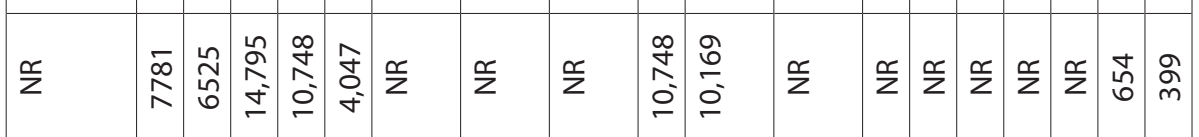

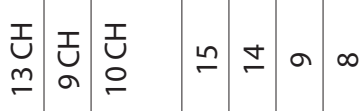

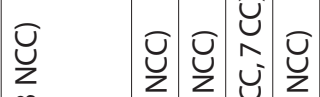

İ

인

운

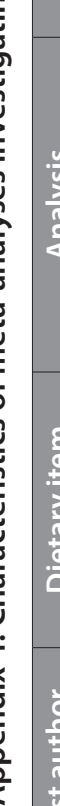

융

先

단 응

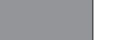

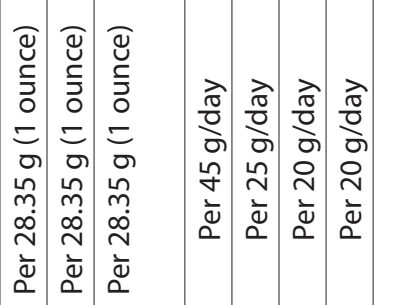

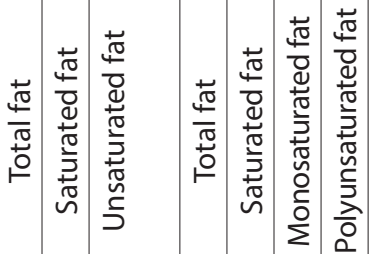

㟧

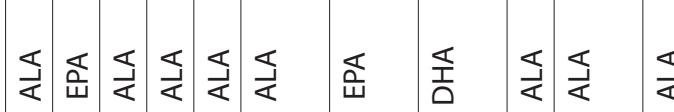

ư

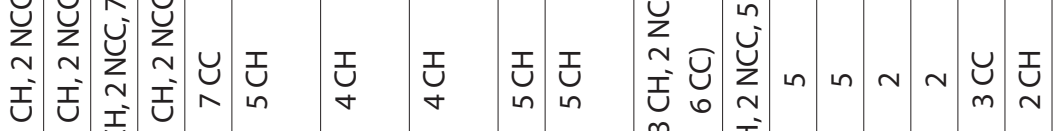

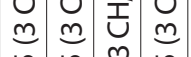

$\stackrel{m}{=}$

$$
\simeq
$$

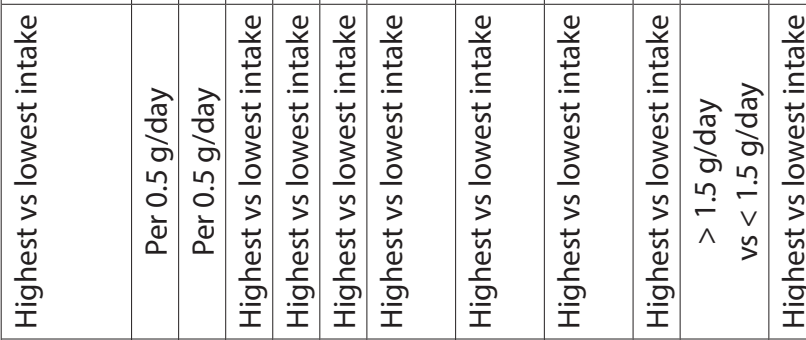

离

竞

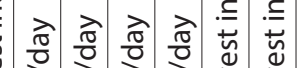

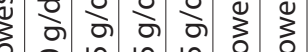

는

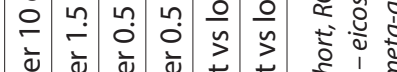

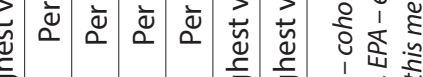

夏

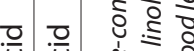

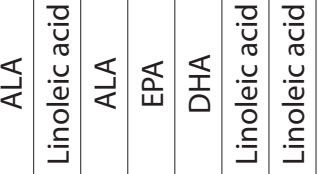

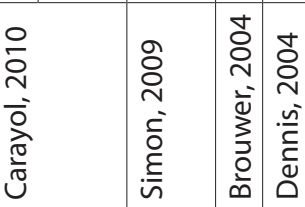




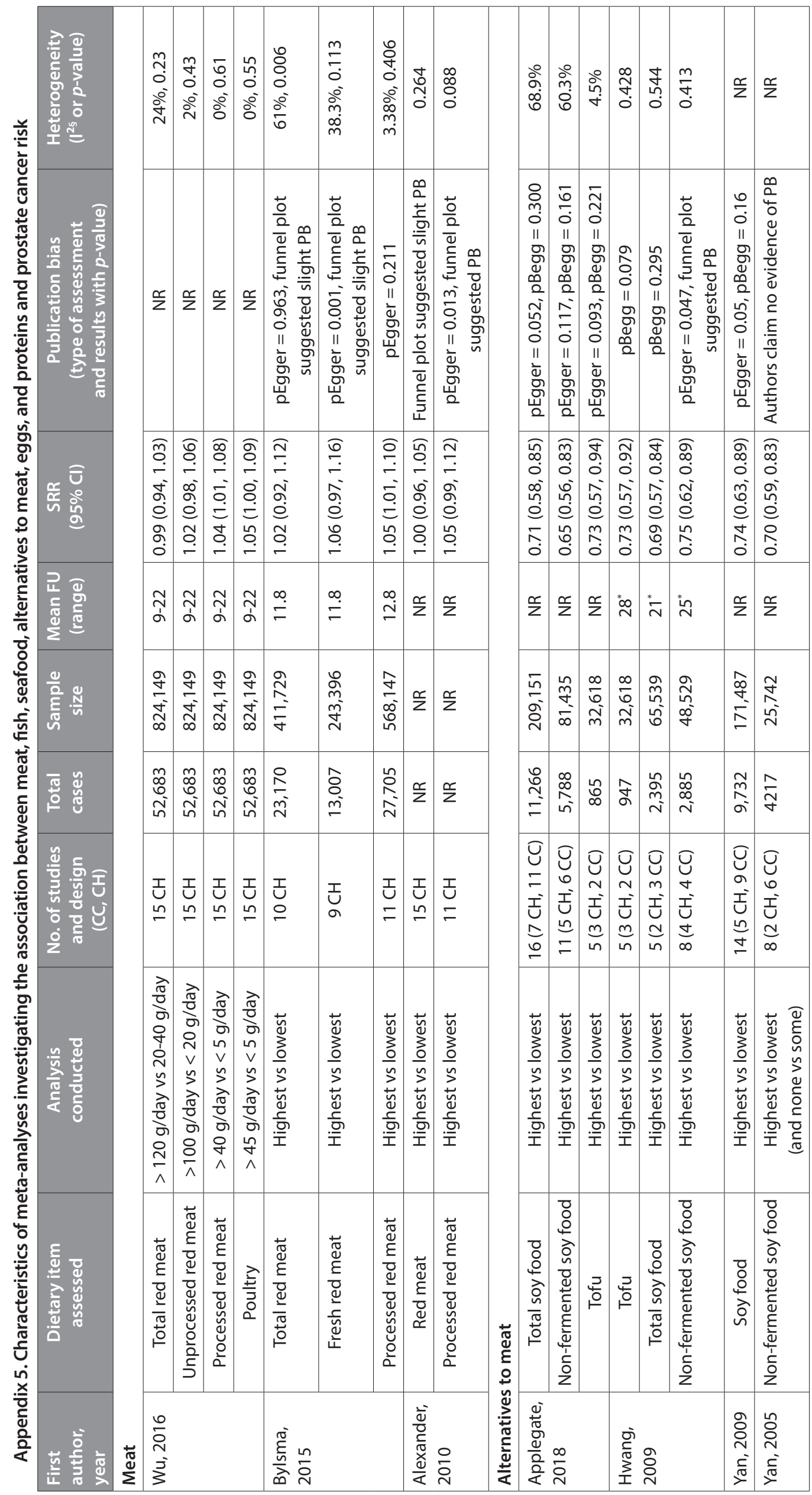




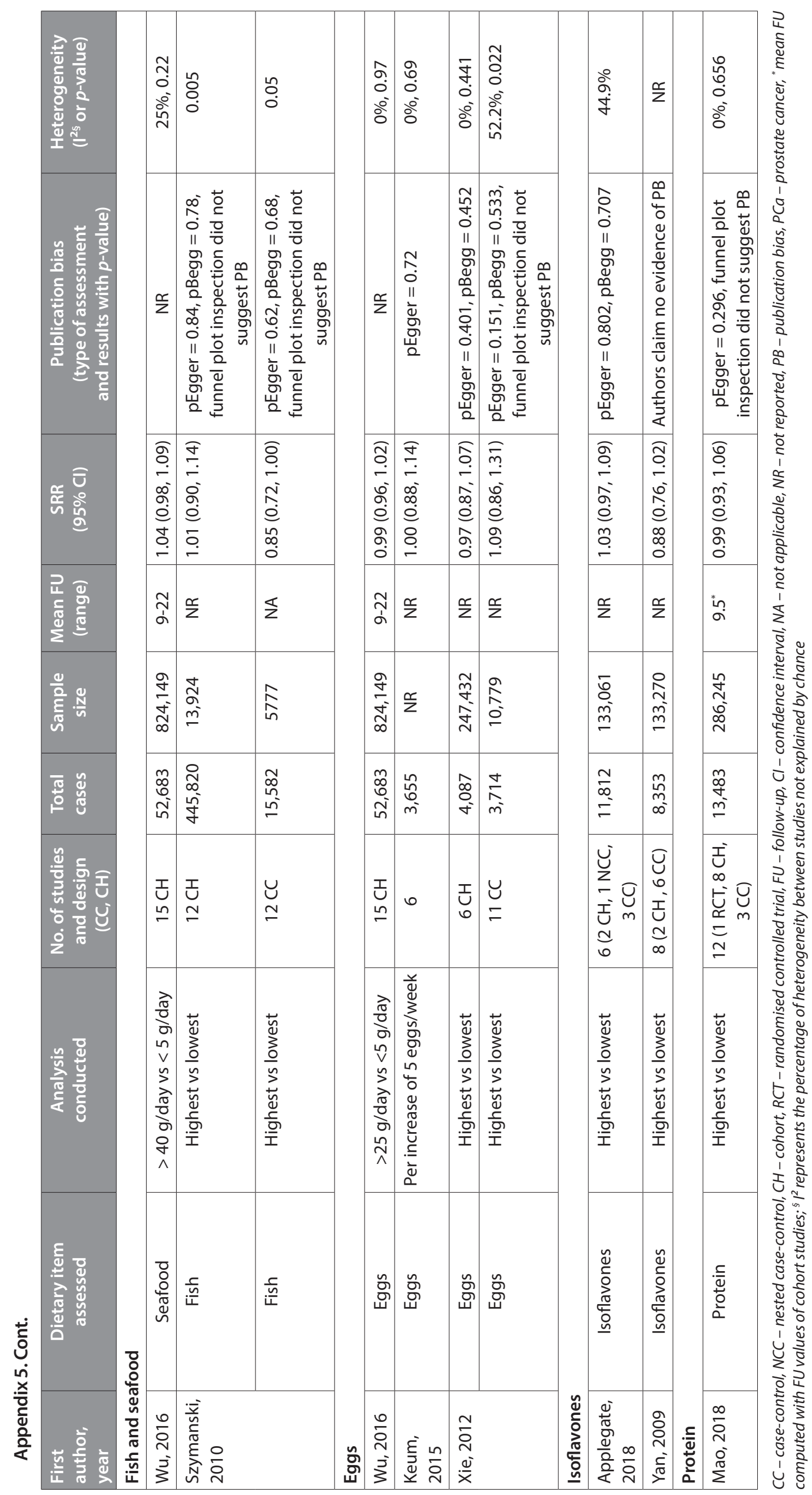




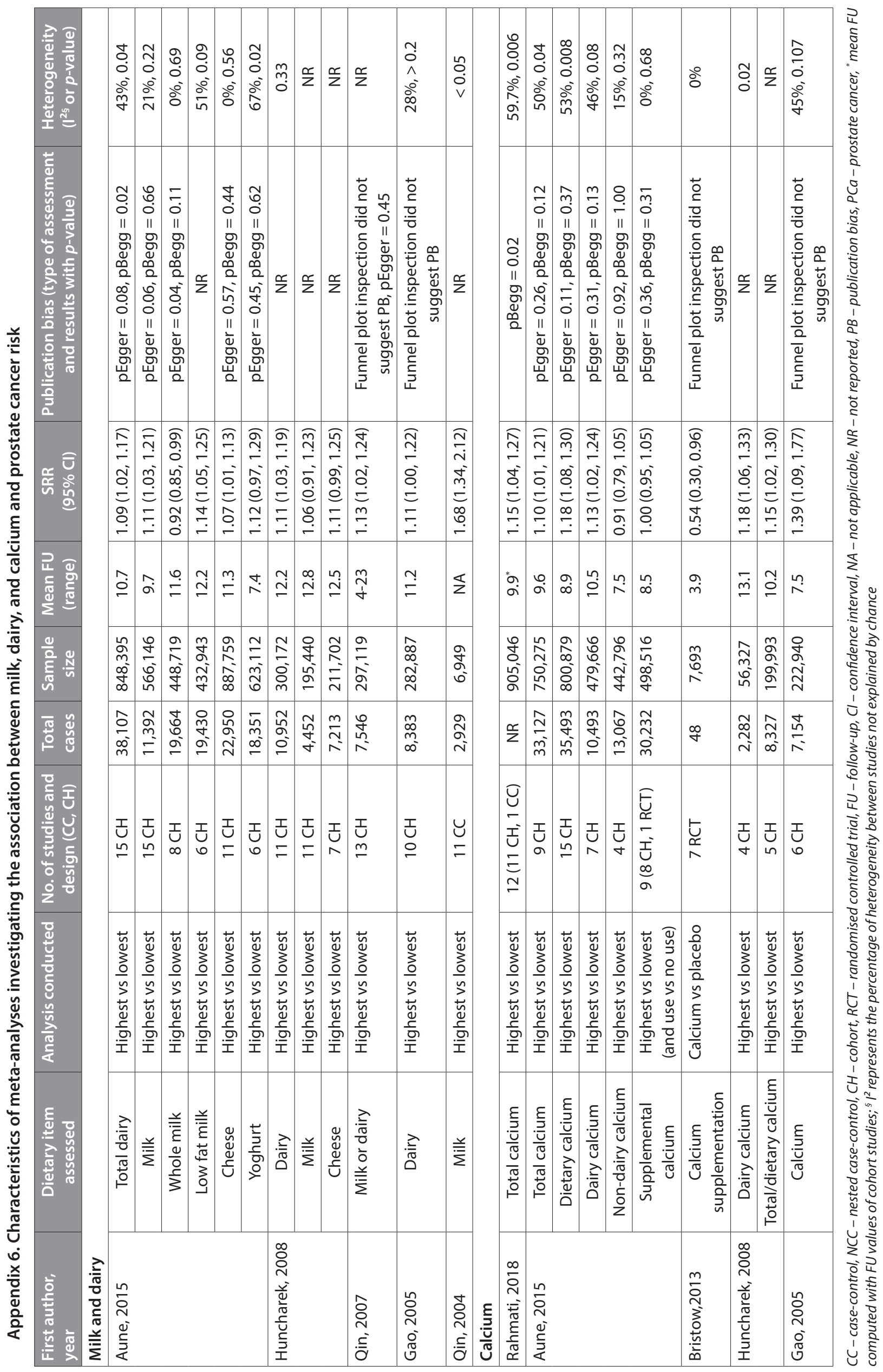




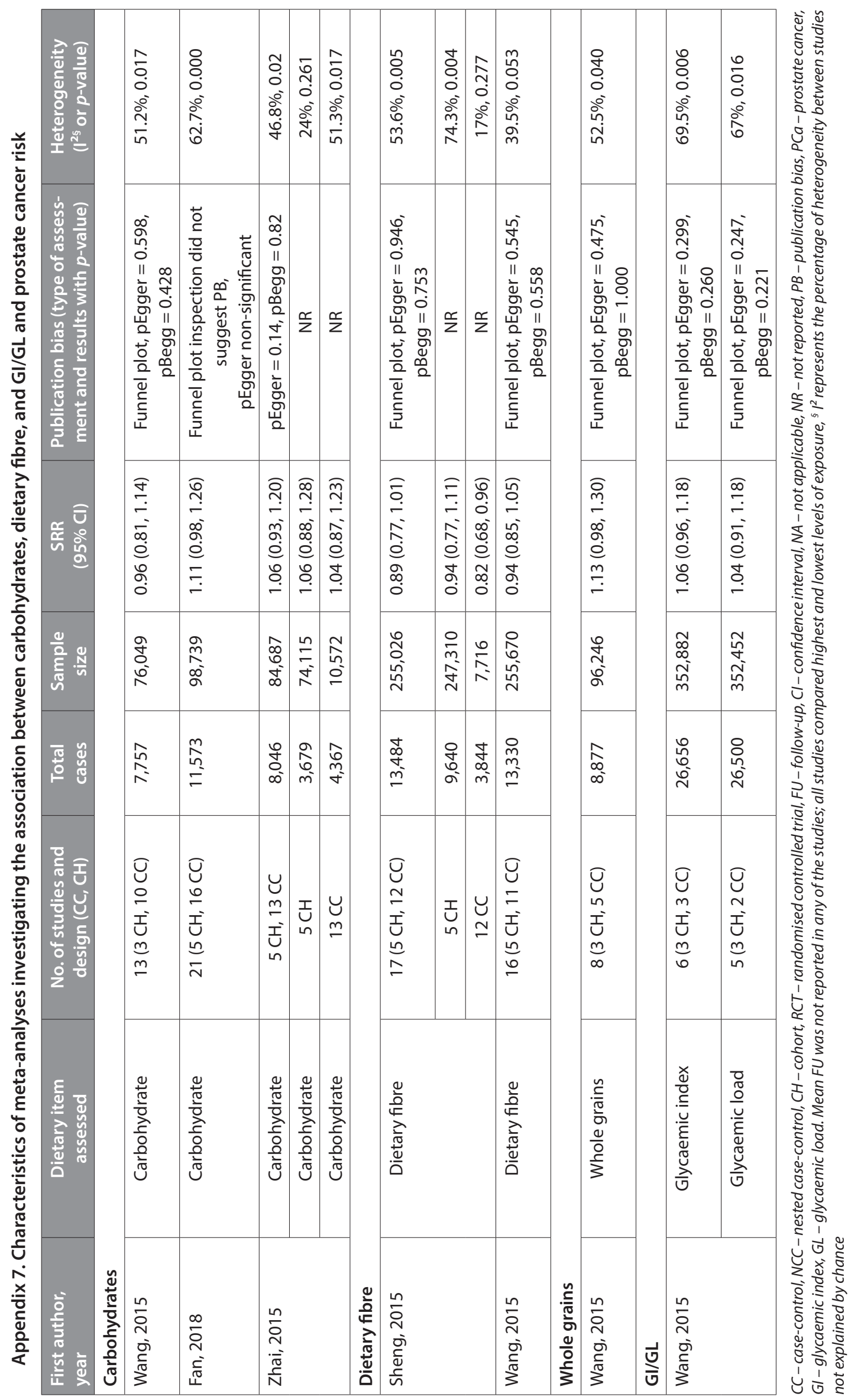




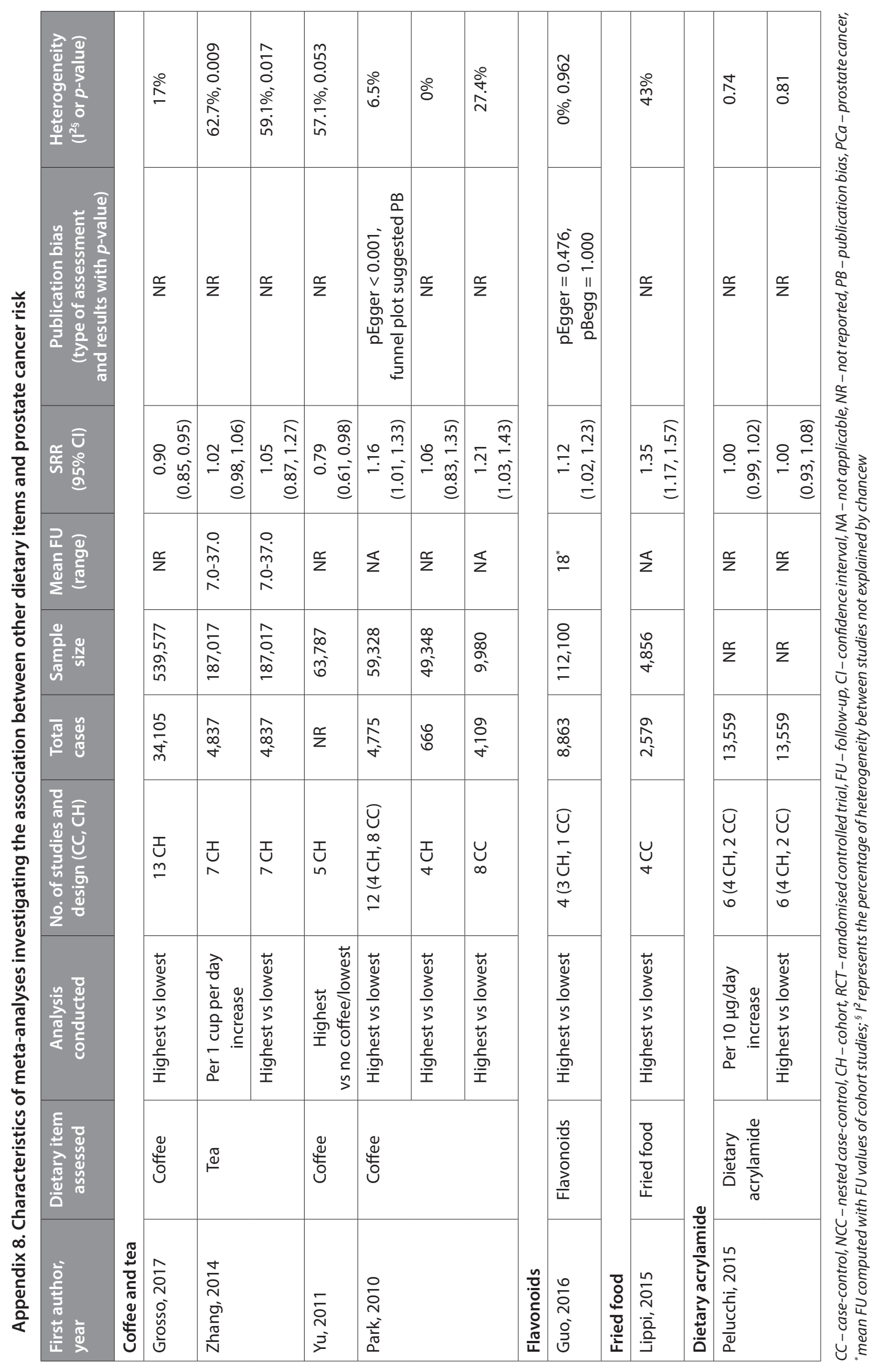




\begin{tabular}{|c|c|c|c|c|c|c|c|c|c|c|c|c|c|c|}
\hline 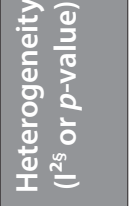 & $\begin{array}{l}\bar{c} \\
\overline{0} \\
\circ \overline{0} \\
\text { in }\end{array}$ & 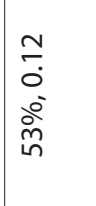 & $\begin{array}{l}\hat{o} \\
0 \\
0 \\
o \\
0\end{array}$ & ठ̊ & $\stackrel{\circ}{\circ}$ & ठ̊ & خิ̀ & ลें & $\begin{array}{l}\stackrel{d}{N} \\
0 \\
0 \\
0 \\
0\end{array}$ & $\begin{array}{l}\bar{\delta} \\
0 \\
0 \\
\vdots \\
0 \\
\dot{0} \\
\stackrel{1}{1}\end{array}$ & $\begin{array}{l}m \\
\tilde{m} \\
0 \\
o \\
o \dot{o}\end{array}$ & 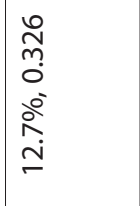 & ঃ̊ & ठ̊ \\
\hline 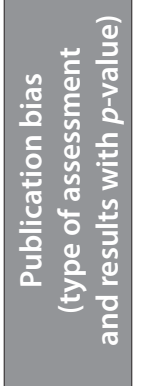 & 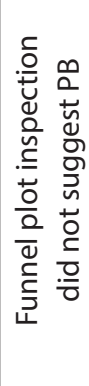 & 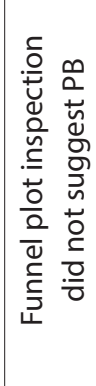 & 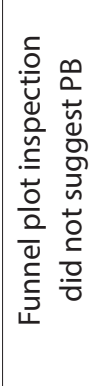 & 告 & 愛 & 愛 & 告 & $\stackrel{\Upsilon}{z}$ & 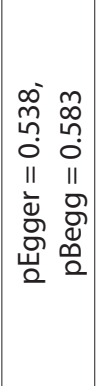 & 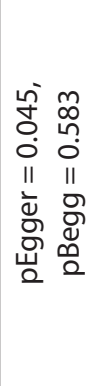 & 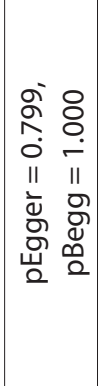 & 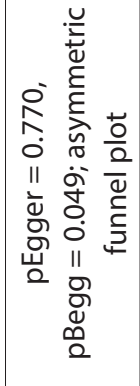 & $\stackrel{\Upsilon}{z}$ & 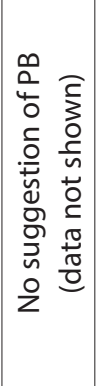 \\
\hline 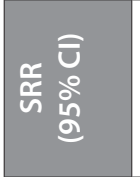 & 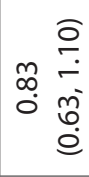 & 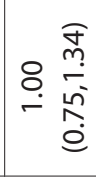 & 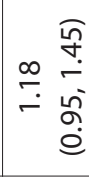 & 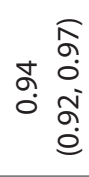 & 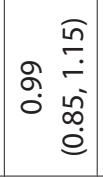 & 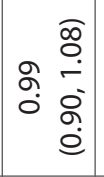 & 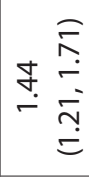 & 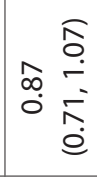 & 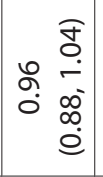 & 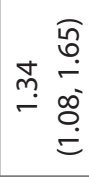 & 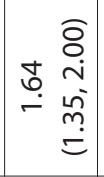 & 范 & 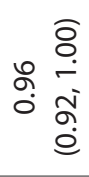 & 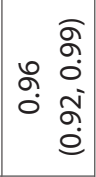 \\
\hline 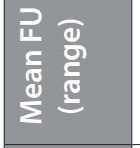 & $\stackrel{m}{\underset{\sim}{\mp}}$ & $\stackrel{m}{\underset{\sim}{\ddagger}}$ & $\overline{\check{I}}$ & $\frac{n}{o}$ & $\S$ & $\stackrel{\cong}{=}$ & 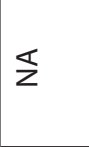 & $\stackrel{\varrho}{=}$ & $\overline{\mathfrak{I}}$ & $\overline{\check{I}}$ & $\stackrel{\S}{z}$ & $\stackrel{*}{\ddot{m}}$ & $\stackrel{\hat{m}}{\underline{m}}$ & $\stackrel{\vec{r}}{\stackrel{m}{r}}$ \\
\hline 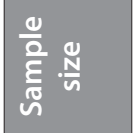 & $\begin{array}{l}\bar{\sigma} \\
\tilde{n} \\
\text { ò }\end{array}$ & $\begin{array}{l}\bar{\sigma} \\
\tilde{m} \\
\delta\end{array}$ & $\begin{array}{l}\hat{\sigma} \\
\text { fं }\end{array}$ & $\begin{array}{l}\frac{0}{6} \\
\frac{1}{0} \\
m\end{array}$ & $\begin{array}{l}\infty \\
0 \\
\infty \\
\infty \\
\infty\end{array}$ & $\bar{m}$ & $\begin{array}{l}\infty \\
0 \\
\infty \\
\infty\end{array}$ & $\frac{\bar{m}}{\bar{c}}$ & $\begin{array}{l}\infty \\
\kappa \\
\hat{n} \\
\end{array}$ & 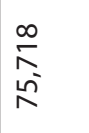 & $\stackrel{\infty}{\underset{f}{\sigma}}$ & $\begin{array}{l}\stackrel{2}{1} \\
m \\
\tilde{o} \\
\dot{q}\end{array}$ & $\begin{array}{l}\nabla \\
\dot{\infty} \\
0 \\
0 \\
m \\
m\end{array}$ & \begin{tabular}{l}
$\infty$ \\
$\stackrel{\infty}{N}$ \\
$\stackrel{2}{\sim}$ \\
\multirow{\gamma}{*}{}
\end{tabular} \\
\hline 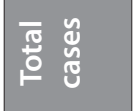 & 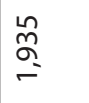 & $\stackrel{\stackrel{n}{n}}{\stackrel{\sigma}{-}}$ & $\stackrel{\infty}{\stackrel{\infty}{f}}$ & $\begin{array}{l}\hat{n} \\
\alpha \\
\dot{\sigma}\end{array}$ & 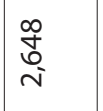 & $\begin{array}{l}\stackrel{0}{\circ} \\
\stackrel{n}{f}\end{array}$ & 孞 & $\begin{array}{l}\stackrel{0}{\circ} \\
\stackrel{n}{f}\end{array}$ & 号 & 等 & $\begin{array}{l}\infty \\
\infty \\
\infty \\
-\end{array}$ & 亲 & $\begin{array}{l}\text { రి } \\
\infty \\
\text { సે }\end{array}$ & $\begin{array}{l}0 \\
\infty \\
\infty \\
\text { N. }\end{array}$ \\
\hline 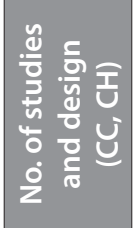 & $\underset{\forall}{I}$ & $\underset{\text { I }}{I}$ & $\underset{\sim}{I}$ & $\underset{\sim}{\mathrm{I}}$ & $\underset{\sim}{\stackrel{U}{\sim}}$ & I & $\underset{\sim}{\cup}$ & $\underset{\mathrm{m}}{\mathrm{I}}$ & 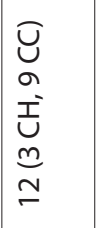 & 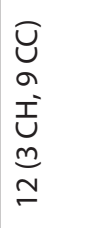 & $\underset{\forall}{\cup}$ & $\begin{array}{l}\bar{U} \\
u \\
I \\
I \\
\text { in } \\
0\end{array}$ & 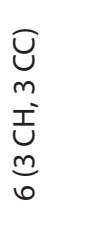 & 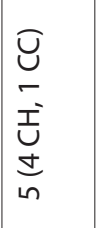 \\
\hline 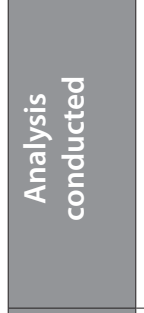 & 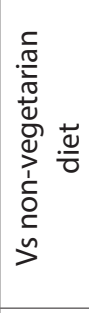 & 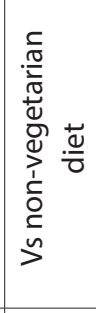 & 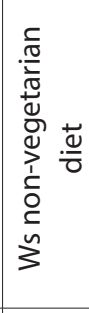 & 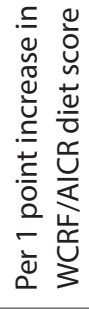 & 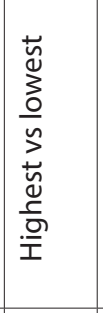 & 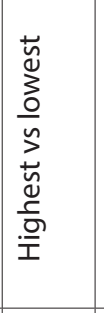 & 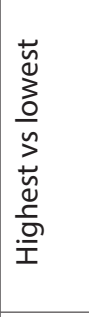 & 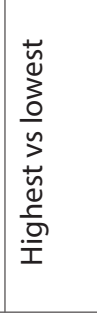 & 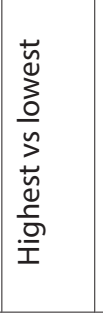 & 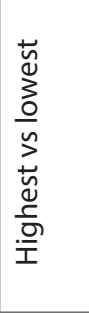 & 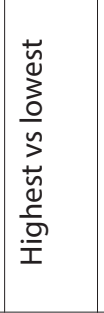 & 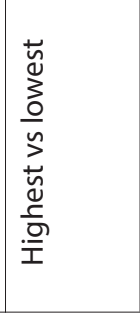 & 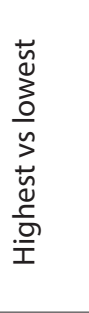 & 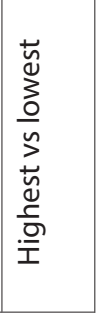 \\
\hline 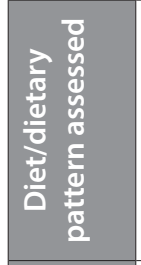 & 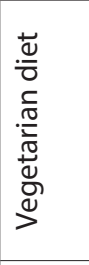 & 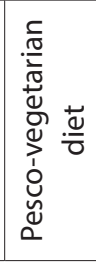 & 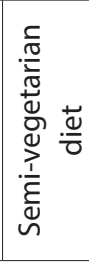 & 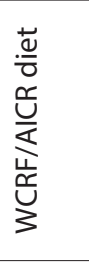 & 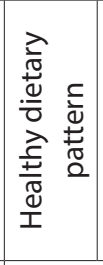 & 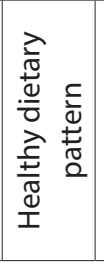 & 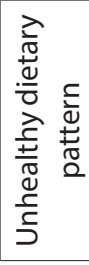 & 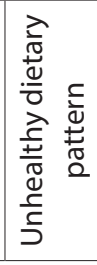 & 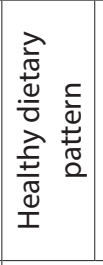 & 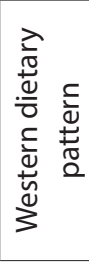 & 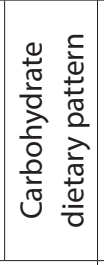 & 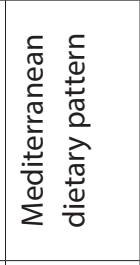 & 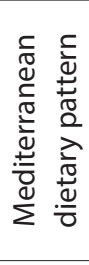 & 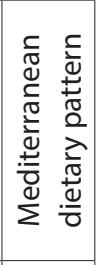 \\
\hline 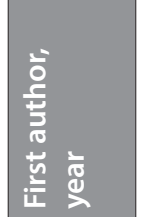 & 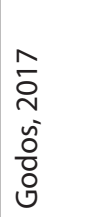 & & & 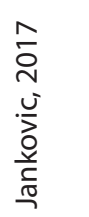 & 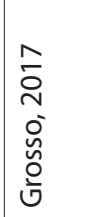 & & & & 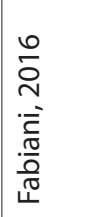 & & & 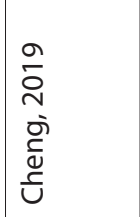 & 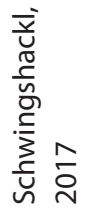 & 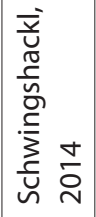 \\
\hline
\end{tabular}

